\title{
Tratamiento y prevención de las enfermedades de transmisión sexual
}

Ernesto Calderón-Jaimes, M.C., M.S.P. ${ }^{(1)}$

L as enfermedades de transmisión sexual (ETS) representan a un grupo de padecimientos infecciosos que se transmiten predominantemente por contacto sexual. Algunos de éstos son considerados como de notificación obligatoria en la mayoría de los países, y continúan teniendo una frecuencia inaceptablemente alta, fundamentalmente entre gente joven en edad reproductiva y con vida sexual activa. ${ }^{1-9}$

Las ETS, y sus complicaciones, no están distribuidas uniformemente entre la población, pues sólo algunos grupos específicos son los que se encuentran en riesgo de adquirirlas o transmitirlas; a ellos se les debe reconocer con el fin de incluirlos en los programas de vigilancia y control. Hay también algunos subgrupos de individuos que sufren particularmente las complicaciones; por ejemplo, las mujeres que inician su actividad sexual a edad temprana y que tienen varias parejas en lapsos cortos. ${ }^{5}$

La mujer embarazada es parte de un grupo especial prioritario para el control de las ETS, ya que estas infecciones pueden llegar a alterar el curso normal del embarazo, el parto, el puerperio y la lactancia, situación que compromete la salud del binomio madrehijo. ${ }^{10}$

Las ETS pueden constituirse en un evento intercurrente adverso en el curso del embarazo. Los patógenos transmitidos sexualmente juegan un papel importante en la etiología del embarazo ectópico, el aborto espontáneo, los mortinatos, la prematurez, de las infecciones congénitas, perinatales y neonatales en el producto in utero y en el recién nacido, así como de las infecciones puerperales maternas. ${ }^{1}$
Los adolescentes son considerados de alto riesgo para adquirir ETS por los motivos siguientes: desarrollan diversas infecciones a temprana edad; tienen relaciones sexuales sin ningún medio de protección; son biológicamente más susceptibles a la infección; tienen mayor posibilidad de contraer infecciones con curso clínico asintomático; son más renuentes a solicitar consulta médica, ya que enfrentan múltiples obstáculos para utilizar los servicios de atención médica y, como agregado, reciben tratamientos empíricos sin una base comprobatoria de la etiología; además, no son sujetos de vigilancia epidemiológica en pareja y, finalmente, son ellos los que sufren las complicaciones tempranas o tardías durante su vida sexual. ${ }^{3}$

El problema de las ETS no se conoce debidamente en México; las pocas clínicas especialmente instaladas con ese propósito atienden a un número muy limitado de hombres y trabajadoras sexuales, de tal manera que la información que se desprende de su actividad no es representativa de lo que ocurre en la población. Sin embargo, se ha estimado que la frecuencia de ETS en la población general fluctúa entre 0.1 y $0.5 \%$; en cambio, para la población considerada como de alto riesgo, se calcula una frecuencia que va de 10 a $20 \%$. La población más afectada se encuentra entre los 18 y 24 años de edad, y la relación hombre-mujer es de entre 7 a 10 por uno. $^{2}$

El propósito de este trabajo es presentar los aspectos más sobresalientes y actualizados del tratamiento y la prevención de las enfermedades adquiridas por contacto sexual; asimismo, se describen las manifestaciones clínicas de las mismas, que son lo suficiente-

(1) División de Medicina Experimental, Instituto $\mathrm{N}$ acional de Pediatría, México. 
mente evidentes como para motivar la consulta médica. Se tomará en cuenta que es el médico general quien tiene el primer contacto con esos pacientes, de tal forma, que se ofrecerán algunos recursos clínicos y de laboratorio que permitan precisar el diagnóstico, respalden el o los esquemas de tratamiento y prevención $\mathrm{y}$, asimismo, faciliten el seguimiento y la vigilancia epidemiológica de la población potencialmente expuesta al riesgo de contacto y transmisión.

\section{Úlceras genitales}

En general, la presencia de lesiones ulcerosas en el área perineo-genital externa llama fuertemente la atención de los pacientes por su localización y, obviamente, por sus manifestaciones clínicas; cuando las lesiones se presentan en la mucosa interna de los genitales pueden no ser reconocidas tempranamente. En el caso de las mujeres, por ejemplo, el padecimiento puede tener un curso asintomático.

Tradicionalmente las llamadas enfermedades venéreas se circunscribían a la gonorrea, la sífilis y el chancroide; no obstante, el panorama ha cambiado debido a que los pacientes con úlceras genitales han aumentado en frecuencia. Por otro lado, puesto que la etiología de estas lesiones se ha complicado, el diagnóstico diferencial -con el fin de discriminarlas de las de la sífilis, el herpes, el chancroide, el linfogranuloma, la clamidiasis, la donovanosis, la condilomatosis y de infecciones mixtas- ha planteado otras dificultades. ${ }^{11}$

La presencia de lesiones ulcerosas se considera como un factor de alto riesgo para adquirir la infección por el virus de la inmunodeficiencia humana (VIH). El médico que atiende a este tipo de pacientes debe prescribir en la primera visita un esquema de tratamiento, tomando como base la impresión diagnóstica más probable, obviamente con la limitante de no tener los resultados preliminares o definitivos de laboratorio.

\section{Chancroide}

El chancroide es producido por el Haemophilus ducreyi, un bacilo gramnegativo que se observa en los frotis con material obtenido de las úlceras como si fuera un "cardumen". Requiere de medios especiales para cultivo, y es oxidasa y catalasa negativo. La sensibilidad del cultivo no es mayor a $80 \%$. Puede ser la etiología de 15 a $25 \%$ de los pacientes con lesiones ulceradas; uno de cada 10 pacientes con chancroide coincide con infección por el virus de herpes o con el Treponema pallidum. El reservorio parece ser la mujer que ejerce la prostitución y, aún más, aquella que tiene lesiones con curso asintomático. No se conoce la frecuencia de la infección en la población general ni en la considerada como de alto riesgo. Se menciona a los países en desarrollo como aquellos en los que la población presenta con más frecuencia el chancroide y, ocasionalmente, se informa de algunos pequeños brotes en grupos cerrados, donde existe promiscuidad y hacinamiento. ${ }^{12}$

El criterio diagnóstico se establece con base en la presencia de úlceras después de siete días del contagio. En ninguna etapa del desarrollo de las lesiones se observa la formación de vesicoúlceras (características del herpes); la lesión es papular enrojecida, edematosa y con dolor progresivo mientras se inicia la formación de la úlcera con bordes circinados poco limitados y con tendencia a coalescer. En esta fase del desarrollo, el dolor es intenso quemante y ardoroso, sobre todo cuando la localización en el hombre se encuentra en el frenillo, el glande, el prepucio y el surco balanoprepucial. En la mujer esta signología llama la atención cuando se establece en el periné, los labios y el introito; en cambio, es menos evidente cuando es interna en vagina y cérvix; se acompaña de leucorrea y en ocasiones hay un discreto sangrado que puede manchar la ropa interior. En la mujer la signología puede ser de tipo urinario con disuria, urgencia y frecuencia en la micción. La frecuencia de lesiones ulcerosas y verdaderas placas ulceradas es mayor en el chancroide que en el herpes. Otra manifestación importante es la respuesta regional de linfadenopatía, que puede llegar a provocar la formación de bubas dolorosas y fluctuantes.,11

Es necesario descartar la sífilis en estos pacientes, por medio del estudio en campo oscuro o por fluorescencia, así como mediante de pruebas serológicas. Igualmente se debe descartar la infección por herpes primario o recurrente; no obstante, cabe aclarar que en este caso las pruebas son poco eficientes sobre todo para el virus del herpes simplex 2 (VHS-2) y, además, las lesiones vesiculares no siempre se encuentran cuando el paciente va a consulta, o bien, éste no refiere su presencia. ${ }^{12}$

El tratamiento cura la infección, resuelve los síntomas clínicos y previene la transmisión. Cuando las lesiones son varias y además profundas, dejan secuelas cicatriciales importantes y evidentes. Para el tramiento se puede seleccionar uno de entre varios fármacos; sin embargo, en la actualidad se ha encontrado que con la administración de una dosis única de $1.0 \mathrm{~g}$ de azitromicina, vía oral, o bien, de ceftriaxona de $250 / 500 \mathrm{mg}$, por vía intramuscular, se logra la curación. El paciente debe ser revisado siete días después del tratamiento; cuando éste es efectivo, a los tres días hay un cambio favorable y muy evidente 
en las úlceras. A las dos semanas, prácticamente, se han resuelto las lesiones. Cuando los bubones persisten con fluctuaciones, requieren ser drenados; si esto no se realiza, la evolución se prolonga e incluso se requiere aplicar un tratamiento más largo con los mismos fármacos. De la misma manera se puede decir en el caso de los pacientes que son seropositivos persistentes al VIH; en ellos la evolución es mucho más lenta, el tratamiento puede no ser efectivo, pueden coincidir otros patógenos e, incluso, es necesario administrar varios esquemas de tratamiento; ello puede hacerse con los mismos fármacos o, inclusive, agregando ciprofloxacina con dosis de $500 \mathrm{mg}$, tres veces al día, durante tres días consecutivos, o bien, incluyendo eritromicina base a $500 \mathrm{mg}$, orales, cada seis horas, durante siete días consecutivos. Esta es una razón para aconsejar a los pacientes con lesiones ulcerosas que acepten realizarse una prueba para determinar $\mathrm{VIH} .{ }^{13}$

Las parejas sexuales con contactos en los 10 días previos a la aparición de las lesiones deben recibir el mismo tratamiento, estén o no presentes signos compatibles con la infección.

\section{Infección genital por el virus del herpes simplex}

El herpes genital es una enfermedad recurrente e incurable, producida por dos serotipos identificados como VHS-1 y VHS-2, aunque la gran mayoría de las infecciones genitales primarias y recurrentes son producidas por el VHS-2. La infección en el humano tiene características diferentes para cada uno de los serotipos, independiente de que las lesiones sean indistinguibles. La transmisión del VHS-2 es fundamentalmente por contacto sexual, donde una de las parejas es portador asintomático de lesiones con poca o nula signología, o bien, es eliminador intermitente de partículas virales infectantes en la mucosa genital; tiene localización fundamentalmente genital, y las recurrencias son frecuentes en más de $65 \%$ de los pacientes. ${ }^{14}$

La prevalencia de infección estimada por la presencia de anticuerpos específicos para el VHS-2 es variable. En México para la población general es menor a $30 \%$; en cambio, para la población de alto riesgo puede ser de más de $60 \%$, cifras muy semejantes a las observadas en otros países. En las mujeres embarazadas, las recurrencias son mayores, por lo que se debe vigilar la presencia de infección primaria o recurrencias durante el último trimestre del embarazo o en los inicios del trabajo de parto. ${ }^{15,16}$
Para establecer el diagnóstico es importante considerar que el periodo de incubación, después del contagio, es de 2 a 7 días cuando aparecen las típicas lesiones vesiculares, pequeñas, límpidas y extraordinariamente frágiles; se rompen rápidamente y dejan pequeñas lesiones ulceradas que coalescen y que, dependiendo del sitio en que aparecen, llaman la atención del paciente por el dolor lacerante. En el hombre las lesiones se presentan en los genitales externos periuretrales, en el prepucio y el surco balanoprepucial $\mathrm{y}$, ocasionalmente, en las zonas perianales; el dolor es ardoroso y punzante. En la mujer las lesiones son de localización vaginal y cervical, por lo que la signología es poco aparente; sin embargo, es posible que se localicen en el introito y los labios, con dolor y molestias semejantes a las del hombre. La mujer puede tener descarga hialina, presencia de pequeñas zonas ulceradas con fondo rojizo y referir incluso la signología urinaria. La enfermedad es autolimitada; la fase aguda con máxima replicación viral dura de 3 a 5 días, y el riesgo de contagio se puede prolongar un mes o incluso más. Posteriormente se establecen cursos de latencia alternados con recurrencias, algunas de las cuales vuelven a tener manifestaciones agudas semejantes a la exposición primaria. Por lo general, no más de uno de cada tres individuos con la infección pueden tener la presencia documentada de lesiones vesiculares. ${ }^{5,14}$

Existe riesgo de infección perinatal, y la ruta de transmisión es ascendente; sin embargo, la mayor frecuencia de contagio del neonato es durante el paso por el canal del parto infectado. Ahora bien, dependiendo del momento de la infección durante el embarazo, es posible que la infección por el VHS-2 se convierta en causa de aborto, o bien, en infección neonatal sistémica grave. ${ }^{16}$

El tratamiento de los pacientes con el primer episodio de infección por herpes incluye la administración de fármacos antivirales y una amplia explicación de la historia natural del herpes genital, de la transmisión sexual y perinatal, así como de los procedimientos para reducir el riesgo de contagio y transmisión. La etiología del primer episodio incluye en 5 a 30\% al VHS-1; las recurrencias son menos frecuentes con este último serotipo que con el VHS-2, aunque para los propósitos del tratamiento no importa el serotipo viral. Los regímenes recomendados para cada uno de los fármacos mencionados son: ${ }^{17}$

Aciclovir $400 \mathrm{mg}$, por vía oral, cada ocho horas, durante 7 a 10 días consecutivos.

Aciclovir $200 \mathrm{mg}$, por vía oral, cinco veces al día, durante 7 a 10 días consecutivos. 
Famciclovir $250 \mathrm{mg}$, por vía oral, cada ocho horas, durante 7 a 10 días consecutivos.

Velaciclovir $1.0 \mathrm{~g}$, por vía oral, cada 12 horas, durante 7 a 10 días.

El tramiento se debe prolongar si la cicatrización no es completa a los 10 días de instaurado. Las dosis más altas del aciclovir se han utilizado en la proctitis herpética, la estomatitis y la faringitis. Durante los episodios de recurrencias se pueden utilizar los mismos medicamentos reduciendo el tiempo de tratamiento a cinco días y a las mismas dosis.

La administración de tratamiento supresivo diario reduce la frecuencia de las recurrencias de herpes genital en más de $75 \%$, sobre todo en aquellos pacientes que tienen antecedentes de recurrencias frecuentes (más de seis por año).

La enfermedad severa, con complicaciones sistémicas, como la neumonitis, la encefalitis o la hepatitis, requiere administración endovenosa de los antivirales; se recomienda utilizar el aciclovir a dosis de $5 / 10 \mathrm{mg} / \mathrm{kg}$ de peso, por vía endovenosa, cada ocho horas, durante 5-7 días o, incluso, hasta que se tenga la resolución clínica. ${ }^{1}$

Las parejas sexuales de individuos con antecedentes de herpes genital deben tener el beneficio de ser evaluados clínicamente y de recibir información en la misma forma que el paciente que cursa con úlceras genitales.

El riesgo de transmitir la infección al producto es máximo cuando la infección primaria se adquiere cercana al término del embarazo (35-50\%), en cambio es menor durante la primera mitad del embarazo (3\%). Todas las embarazadas deben ser evaluadas y cuidadosamente examinadas durante la fase de labor del parto, sobre la presencia de lesiones vesiculares o úlceras en genitales. La presencia de herpes neonatal se debe manejar como una verdadera urgencia, administrando aciclovir, $30-60 \mathrm{mg} / \mathrm{kg} /$ día, durante $10-20$ días. $^{16}$

La prevención del contagio de herpes genital debe considerar lo siguiente:

1. Todos los pacientes con herpes genital deben ser informados con precisión de la historia natural de la enfermedad -haciendo hincapié en el riesgo potencial de recurrencias-, así como de la eliminación periódica de partículas virales durante la fase asintomática sin marcadores de actividad clínica, lo cual representa un riesgo importante de transmisión a la pareja sexual.

2. El paciente con herpes genital debe ser advertido de abstenerse de la actividad sexual cuando existan lesiones activas, para lo cual debe informar a la pareja sexual sobre la posibilidad de que ambos tengan la misma enfermedad. El uso del condón con una pareja nueva o no infectada debe ser obligatorio.

3. La transmisión de la enfermedad puede ocurrir durante los episodios asintomáticos, lo cual es más frecuente cuando el antecedente de herpes genital tiene un lapso menor a un año.

4. El riesgo perinatal de infección debe ser perfectamente explicado a la pareja sexual. La mujer con antecedentes de herpes genital debe hacerlo saber a su obstetra durante el embarazo.

\section{Sífilis}

La sífilis es una enfermedad sistémica causada por el Treponema pallidum; se caracteriza por fases de actividad y prolongados periodos de latencia, condiciones que deben ser tomadas en cuenta para el desarrollo y la interpretación de las pruebas de laboratorio. La transmisión se realiza por medio de contacto directo de las membranas mucosas o de las infecciones de la piel con lesiones infectadas húmedas.

El paciente que tiene sífilis acude en demanda de atención médica por signos y síntomas de infección primaria (presencia de úlcera o chancro en el sitio de la inoculación); infección secundaria (sífilis florida, donde sobresale la erupción mucocutánea con lesiones húmedas aparentes, y hay una respuesta sistémica de la infección en órganos como hígado y ganglios regionales), o sífilis terciaria (con compromiso crónico y con afección cardiaca, neurológica, oftálmica, auditiva o presencia de lesiones gomosas). La infección puede reconocerse por la práctica de reacciones serológicas para la sífilis durante la fase de latencia. Se considera como sífilis latente temprana, aquella que se adquirió dentro del año previo a la reacción. Todos los demás casos se consideran como sífilis tardía o de duración no conocida. ${ }^{18}$

La enfermedad es más frecuente en la población joven y altamente promiscua, que tiene la actividad sexual sin ninguna protección, con cambios frecuentes de pareja, y que puede ser adicta a las drogas. ${ }^{18}$

La infección del producto in utero ocurre cuando la madre presenta espiroquetemia recurrente periódica, y el feto se puede ver afectado dependiendo de la fase del embarazo. El contagio al nacimiento es posible cuando el producto se expone al canal del parto infectado. ${ }^{19}$ La población de mayor riesgo se observa en grupos de hombres con prácticas homosexuales y en mujeres que ejercen la prostitución. ${ }^{20,21}$

La sífilis adquirida se presenta después de un periodo de incubación promedio de tres semanas $(10 \mathrm{a}$ 
90 días), se inicia con una pápula indurada en el sitio de inoculación, que progresa rápidamente hasta formar una lesión ulcerada simple, no dolorosa, húmeda, indurada, la cual corresponde al chancro. En ocasiones puede haber varias lesiones. La localización habitual son los genitales, pero puede presentarse en el ano, la boca o cualquier sitio de contacto con el treponema. La lesión es autolimitada y cura en 3-12 semanas; deja una cicatriz evidente y se presenta una reacción ganglionar evidente e indolora. Las lesiones húmedas representan la fase más infectante, ya que la secreción que cubre las úlceras contiene una gran cantidad de treponemas que pueden visualizarse en el microscopio con campo oscuro., ${ }^{5,18}$

La sífilis secundaria o florida se presenta, en promedio, ocho semanas después de la latencia. Se caracteriza por lesiones papulares infiltradas de aspecto rojizo, conocidas como pénfigo palmoplantar; al palparlas se pueden sentir como bolitas duras bajo la piel infiltrada y edematosa. Las mucosas se ven comprometidas por lesiones papuloescamosas y foliculares, $\mathrm{y}$ la evidencia más llamativa se localiza en la mucosa oral y nasal, y en el recto. ${ }^{5,18}$

La sífilis terciaria se caracteriza por lesiones granulomatosas que se pueden encontrar en cualquier órgano o tejido. Prácticamente son lesiones sin actividad y obviamente sin presencia del T. pallidum. ${ }^{5,18}$

El recién nacido presenta la sífilis florida mucocutánea y visceral. Puesto que la sífilis es una enfermedad tratable, se puede afirmar que la de tipo congénito es producto de la falta del control prenatal durante el embarazo. ${ }^{19}$

El diagnóstico definitivo es la observación del treponema en frotis directo del contenido de las lesiones húmedas, observadas al microscopio con campo oscuro, o bien, con anticuerpos fluorescentes. ${ }^{2}$

El diagnóstico presuntivo se realiza por medio de pruebas serológicas: no treponémicas VDRL (venereal disease research laboratory, por sus siglas en inglés) o RPR (reaginas rápidas en plasma), treponémicas con anticuerpos fluorescentes (FTAB-ABS) y la microaglutinación con anticuerpos para T. pallidum (MHA-TP).,21

La utilización de solamente una de estas pruebas es insuficiente para el diagnóstico, debido a la variedad de falsas positivas en las no treponémicas; sin embargo, los títulos elevados de estas pruebas, usualmente se correlacionan con la actividad de la enfermedad. Es conveniente realizar otras pruebas de seguimiento con la misma técnica y, de ser posible, en el mismo laboratorio. Eventualmente el tratamiento negativizará estas pruebas; no obstante, en algunos pacientes, después del tratamiento, pueden permanecer reactivas a títulos bajos y sin cambio por muchos años. Las pruebas treponémicas positivas continúan así prácticamente durante toda la vida, independiente del tratamiento. La positividad no está relacionada con la actividad de la enfermedad. Cuando el tratamiento se realiza tempranamente en pacientes con sífilis primaria reciente sintomática, entre 15 y $25 \%$ puede negativizarse después del tratamiento a los 2-3 años. Las pruebas treponémicas no deben ser utilizadas para evaluar el éxito o el fracaso del tratamiento. ${ }^{5}$

El tratamiento es a base de penicilina para cualquier estado de la enfermedad. Para el adulto con sífilis primaria o secundaria se utiliza la penicilina benzatina G; 2.4 millones de unidades por vía intramuscular, en dosis única. En niños se administra el mismo tipo de penicilina en única dosis de 50000 unidades por kilo de peso, intramuscular., ${ }^{82}$

Cuando existe alergia a la penicilina, se indica la doxiciclina a $100 \mathrm{mg}$, por vía oral, cada 12 horas, durante dos semanas. La sífilis latente se trata con ese mismo tipo de penicilina, 7.2 millones de unidades, administrada en dosis semanarias de 2.4 millones. En niños con latencia desconocida se administran 50000 unidades por kilo intramuscular hasta un total de 2.4 millones en aplicaciones fraccionadas cada semana. ${ }^{8,22}$

El tratamiento de la sífilis durante el embarazo cura la enfermedad en la madre y la del producto in utero. El fármaco de elección es también penicilina benzatina en dosis semejante a la del paciente adulto. ${ }^{19}$

La sífilis congénita se considera una emergencia por su gravedad y por las complicaciones sistémicas que puede llegar a tener. El tratamiento es con penicilina cristalina acuosa G, de 100000 a 150000 unidades por kilo por día y por vía intravenosa, cada 12 horas durante los primeros siete días y luego cada ocho horas hasta cubrir un total de 10 días. Como posibilidad, se puede aplicar penicilina procaína G: 50000 unidades por kilo, por dosis intramuscular, diaria, durante 10 días. Es conveniente vigilar la posibilidad de compromiso neurológico. Las pruebas de VDRL o RPR en el líquido cefalorraquídeo son valiosas, lo mismo que la FTA-ABS. ${ }^{5,19}$

La transmisión del T. pallidum ocurre sólo cuando están presentes las lesiones húmedas mucocutáneas, que son infrecuentes después del año posterior a la infección; sin embargo, las personas expuestas sexualmente a un paciente que tiene sífilis en cualquier etapa debe ser evaluada clínica y serológicamente.

\section{Enfermedad masculina caracterizada por uretritis}

Consiste en la inflamación de la uretra, de tal forma que se produce una sensación ardorosa al momento 
de orinar; asimismo, hay una descarga hialina espesa o francamente purulenta. La etiología para fines prácticos se circunscribe a Neisseria gonorrhoeae y Chlamydia trachomatis. Desde el punto de vista clínico, puede tratarse de uretritis gonocócica o no gonocócica; esta última, si se descarta la posibilidad de clamidia, puede ser ocasionada por micoplasmas genitales como el Ureaplasma urealyticum y Myclopasma genitalium.

\section{Uretritis gonocócica}

Es el prototipo de las llamadas enfermedades venéreas. Cabe aclarar que el humano es el único huésped de la N. gonorrhoeae, la cual tiene un especial tropismo por las mucosas. El hombre alcanza de 20 a $40 \%$ de riesgo de contagio si tiene una relación sexual con una mujer que padece gonorrea endocervical. En cambio, el riesgo aumenta a $50 \%$, si la mujer tiene relación con un hombre que presenta uretritis gonocócica. ${ }^{23}$

El diagnóstico es clínico. El estudio de una muestra uretral tomada con hisopo para bacterioscopía con tinción de gram es de alto valor diagnóstico si se demuestra la presencia de un proceso inflamatorio con polimorfonucleares dominando el campo y diplococos gramnegativos en forma de riñón o granos de café. El gonococo es muy lábil al calor, a los cambios de temperatura, a la humedad y al $\mathrm{pH}$. El cultivo a partir de secreciones genitales es la prueba deseable siempre que sea posible, al igual que las reacciones serológicas como la coaglutinación, la fluorescencia y algunas variantes de tipo ELISA (ensayo inmunoenzimático, por sus siglas en inglés). ${ }^{23,24}$

El tratamiento de la infección gonocócica no complicada, resistente a la penicilina, se hace a base de ceftriaxona $500 \mathrm{mg}$, en dosis única; otras opciones son la ciprofloxacina $500 \mathrm{mg}$, por vía oral y en una sola dosis; la azitromicina $1.0 \mathrm{~g}$, por vía oral, en dosis igualmente única, o la doxiciclina $100 \mathrm{mg}$, cada 12 horas, por vía oral, durante siete días. ${ }^{8,25,26}$

Se debe ofrecer atención, vigilancia y seguimiento a las parejas sexuales de estos pacientes, con el fin de que reciban atención médica y tratamiento semejante.

\section{Uretritis no-gonocócica}

La inflamación uretral por otros patógenos diferentes a $N$. gonorrhoeae es tan sintomática e indistinguible en su fase aguda como la gonorrea misma. La C. trachomatis ha sido identificada como la causa de 25 a $55 \%$ de los casos, y le siguen los micoplasmas genitales, Trichomonas vaginalis y Gardnerella vaginalis. ${ }^{27}$
El diagnóstico se centra fundamentalmente en evaluar la presencia de gonorrea y clamidia; para esta última la sospecha se tiene cuando se analiza una muestra uretral y únicamente se encuentra exudado inflamatorio sin los diplococos intra y extracelulares. Las pruebas con anticuerpos fluorescentes y algunas variantes de tipo ELISA son de gran apoyo.

Para el tratamiento de este tipo de uretritis se indica la azitromicina $1.0 \mathrm{~g}$, por vía oral, en dosis única, o la doxiciclina $100 \mathrm{mg}$, por vía oral, cada 12 horas, durante siete días. Como alternativas están: la eritromicina base $500 \mathrm{mg}$, por vía oral, cada seis horas, durante siete días; la ofloxacina $300 \mathrm{mg}$, cada 12 horas, durante siete días. ${ }^{8}$

Los pacientes deben ser revaluados después del tratamiento con el fin de documentar el éxito o el fracaso del mismo. Se les debe insistir en abstenerse de relaciones sexuales durante los tratamientos. La pareja sexual debe someterse a evaluación clínica y recibir tratamiento.

\section{Uretritis persistente}

Ante la presencia de las mismas manifestaciones después de uno o varios tratamientos, y ante las recurrencias frecuentes, se requiere certificar el cumplimiento por parte del paciente, y de las parejas sexuales potenciales, de todas las medidas preventivas.

El diagnóstico debe descartar la presencia de T.vaginalis, G. vaginalis y micoplasmas genitales. El tratamiento de primera elección es a base de metronidazol $2.0 \mathrm{~g}$, por vía oral y en dosis única, más eritromicina base $500 \mathrm{mg}$, cada seis horas, administrada por vía oral durante siete días. Como otra opción está el mismo metronidazol combinado con ofloxacina de $300 \mathrm{mg}$, en dosis única, por vía oral. ${ }^{27}$

\section{Uretritis y mucocervicitis purulenta}

Se caracteriza por inflamación de la mucosa uretral con exudado visible, o bien, del canal endocervical, que se encuentra edematoso y friable, y que fácilmente sangra con cualquier contacto. La signología en la mujer es con pesadez pélvica, disuria, urgencia, frecuencia y descarga vaginal y/o uretral. La búsqueda de la etiología se centra fundamentalmente en descartar N. gonorrhoeae o C. trachomatis. El frotis con tinción de gram tiene mucho menos valor que en el hombre, por lo cual se debe intentar recuperar en cultivo. ${ }^{5}$

El tratamiento de la uretritis en la mujer se realiza con los mismos medicamentos que los utilizados en el hombre. A diferencia de éste, la uretritis y la mu- 
cocervicitis en la mujer pueden tener pocas manifestaciones clínicas, sobre todo cuando la descarga vaginal es poco aparente y no la limita en su actividad sexual. A menudo se asocia la presencia de sangrado, sobre todo después de la relación sexual, motivo suficiente para demandar atención médica. Con frecuencia, a veces más de la deseada, no es posible documentar alguno de los patógenos considerados en las ETS, a pesar de que la mucocervicitis sea muy aparente o de que la signología urinaria ocupe una parte importante de la queja o, incluso, a pesar de la administración variada de esquemas de tratamiento. En estos casos, al igual que en los de uretritis persistente en el hombre, se debe valorar con cuidado el cumplimiento de las medidas de prevención; además, es necesario valorar la participación -si es que existe- del dispositivo intrauterino, de lesiones cervicales como el ectropión, del uso de tampones o de sustancias germicidas y espermatocidas. ${ }^{1}$

El tratamiento debe ser administrado después de una evaluación clínica minuciosa y de tener acceso a los exámenes de laboratorio mencionados para descartar las uretritis no gonocócicas. El tratamiento debe enfocarse primero en gonorrea y luego en clamidia. La ceftriaxona $500 \mathrm{mg}$, en dosis única, I.M., seguida de metronidazol $2.0 \mathrm{~g}$, en dosis también única oral, $\mathrm{u}$ ofloxacina $300 \mathrm{mg}$ oral, igualmente en una sola dosis, ueden ser útiles para ello. Se debe evaluar el resultado y, sobre todo, vigilar el contacto con la pareja sexual, la cual debe recibir tratamiento en la misma forma. Las infecciones por clamidia pueden tener recurrencias después de 2 a 4 semanas de haber recibido el tratamiento; esto acontece sobre todo en las adolescentes, las cuales deben vigilarse estrechamente por las potenciales secuelas posteriores durante el embarazo. ${ }^{1,8}$

\section{Riesgo perinatal por patógenos que producen uretritis o cervicitis gonocócica o no gonocócica}

La embarazada con antecedentes de ETS se debe considerar como de alto riesgo desde el inicio de su embarazo; debe ser sometida a escrutinio de actividad y es necesario ofrecerle el diagnóstico oportuno con base en las pruebas de laboratorio disponibles. El riesgo mayor se presenta durante el tercer trimestre, cuando se puede presentar en la madre reactivación de diversos procesos como infección urinaria o cervicovaginitis. Esto puede ser motivo de ruptura prematura de membranas, parto pretérmino, fiebre posparto, enfermedad inflamatoria pélvica y extensión al producto. ${ }^{28}$

El recién nacido puede presentar infección de mucosas por gonorrea (local -conjuntivitis-, o sisté- mica), padecimiento que puede llegar a convertirse en un problema agudo y grave. El diagnóstico se sospecha con un frotis y se comprueba con cultivo; se pueden utilizar las pruebas de coaglutinación o de fluorescencia. El tratamiento es a base de ceftriaxona $125-250 \mathrm{mg}$, por vía I.M., durante tres días consecutivos. ${ }^{10}$

La colonización de patógenos no gonocócicos se produce por clamidia, en primer lugar, y por micoplasmas genitales y G.vaginalis, en segundo. El diagnóstico de clamidia en secreción conjuntival es de gran valor, así como las pruebas fluorescentes o de ELISA. Algunos niños pueden tener diseminación neumónica por clamidia o micoplasmas, aun después del tratamiento de la conjuntivitis. A los niños se les debe administrar azitromicina $5-10 \mathrm{mg} / \mathrm{kg}$ por día, durante cinco días, o eritromicina base $20-50 \mathrm{mg} / \mathrm{kg}$, cada 12 horas, por vía oral, durante 7 a 10 días. ${ }^{5,10}$

\section{Tricomoniasis}

Es producida por el protozoario T. vaginalis, y la frecuencia es elevada en la población general de mujeres en etapa reproductiva, con vida sexual activa; se adquiere por contacto sexual. La leucorrea es amarillo verdosa; la paciente presenta prurito, disuria, dispareunia, eritema vaginal y lesiones hemorrágicas puntiformes que dan al cuello uterino aspecto de "frambuesa". El diagnóstico es por medio de la observación microscópica directa de la secreción vaginal mezclada con solución salina. El examen es positivo cuando está presente el protozoario en forma de pera con movimiento flagelar, además de células polimorfonucleares. El cultivo no es un procedimiento de rutina. El tratamiento es a base de metronidazol $2.0 \mathrm{~g}$ orales en dosis única, o, como alternativo, el mismo medicamento pero a $500 \mathrm{mg}$, cada 12 horas, por vía oral y por siete días consecutivos. Este tratamiento mitiga la signología y conduce a una curación en el 90-95\%.2,8

\section{Infección por los virus del papiloma humano}

En los últimos años se ha demostrado la importancia del virus del papiloma humano (VPH), que se adquiere por contacto sexual, así como del riesgo potencial que tiene de funcionar como un cofactor en el cáncer cervicouterino. Los llamados condilomas perineogenitales se encuentran con cierta frecuencia en la población general, aunque es más común en la considerada como de alto riesgo. El condiloma se define como una formación acuminada o como una carnosidad suave de aspecto como coliflor. En el hombre se localizan en la uretra terminal, el glande, el prepucio, el surco bala- 
noprepucial, el recto y el margen anal. En la mujer se sitúan entre los labios mayores y menores, en el periné, la vagina y el cérvix. El diagnóstico es clínico, por medio de la presencia de las lesiones que son asintomáticas; en ocasiones forman placas queratósicas. En la mujer pueden presentarse como lesiones exofíticas, pequeñas placas o zonas ulceradas. Las lesiones en el cérvix se ulceran con más frecuencia y sangran fácilmente. $^{29}$

La citología con tinción de Papanicolaou identifica las formaciones coilocitóticas o la franca displasia cervical. La histoquímica y la histología de las biopsias comprueba las lesiones de los VPH. El tratamiento no cura la infección ni garantiza la eliminación viral; lo único que se obtiene es la eliminación de las lesiones exofíticas y las placas condilomatosas. La podofilina al 5-10\% en tintura es efectiva en lesiones no muy extensas. Se aplica por pincelaciones, se deja unas cuatro horas y se lava para evitar la irritación química. Se aplica cada semana hasta la desaparición total de las lesiones. Cuando éstas son mayores requieren de tratamiento a base de crioterapia o cirugía con láser. A las mujeres con condilomatosis cervical se les recomienda vigilancia estrecha por medio de citologías. No existe tratamiento específico contra el $\mathrm{VPH} .{ }^{30}$

\section{Prevención de las enfermedades de transmisión sexual}

La educación sexual y la participación en el autocuidado de la salud sexual son procedimientos considerados como altamente efectivos. La abstinencia sexual durante la presencia de lesiones activas o durante los lapsos de tratamiento, tanto para el paciente como para la pareja sexual, es un procedimiento que propicia la curación y evita la transmisión. El uso correcto del condón es una alternativa igualmente confiable para evitar la transmisión de estas infecciones.

Por otra parte, se hacen esfuerzos para obtener algunas vacunas en contra de las ETS,;1 sin embargo, los trabajos de campo no permiten predecir cuándo se tendrán disponibles vacunas eficientes, por lo menos para la población que se encuentra en mayor riesgo de adquirirlas.

Tres aspectos han sido cruciales para aumentar y mantener el interés en las enfermedades adquiridas por contacto sexual: a) la presencia del síndrome de inmunodeficiencia adquirida producido por el VIH; b) la resistencia progresivamente creciente a los antimicrobianos principalmente de N. gonorrhoeae, Haemophilus ducreyi y algunos otros patógenos urogenitales, y c) la fuerte evidencia de que las ETS (ulcerativas y no ulcerativas) condicionan cofactores críticos en la ad- quisición y transmisión del VIH, ya que proveen de una puerta de entrada más accesible al contacto con las secreciones genitales y el VIH, así como el reclutamiento de linfocitos $\mathrm{T}$ activados que funcionan con sus marcadores de receptor CD4+. Esta situación ha permitido a los organismos de salud internacionales enfocar no sólo la atención sino los recursos hacia las ETS tradicionales, teniendo como propósito reducir la morbilidad a fin de incidir en la transmisión del VIH.

Entre los aspectos preventivos más rentables está el reconocimiento temprano de la enfermedad, la utilización de nuevos y más potentes antimicrobianos, cambios positivos en la conducta para aceptar el uso del condón y, por supuesto, el paradigma de la prevención, que es la inmunización por medio de vacunas, ya que ellas ofrecerían una solución eficiente y a largo plazo para controlar las ETS. ${ }^{31-34}$

El esfuerzo tiene como eje central el diseño de inmunógenos para estimular la inmunidad humoral y fundamentalmente en mucosas.

Varios factores son tomados en cuenta: a) la naturaleza del microrganismo (su complejidad); b) la naturaleza de la infección (aguda o crónica); c) la habilidad del organismo para desarrollar la inmunidad natural después de la infección; d) la posibilidad de que el microrganismo sea cultivable; e) el grado de diversidad antigénica; f) la posibildad de obtener modelos experimentales reproducibles, y g) evitar que las infecciones subclínicas evadan el sistema inmune.

Siffilis. El organismo se propaga en conejos, donde se ha demostrado que la inmunidad específica es por lifoncitos $\mathrm{T}$ secretores de citocinas que activan a los macrófagos. Dos proteínas se estudian como inmunógenos la TpN19 y la TpN36, acopladas en el BCG como vector. La inmunización con estos productos induce en el conejo inmunidad mediada por células $\mathrm{T}$ en contra de los antígenos del T. pallidum. Estos estudios son alentadores para especular sobre su utilización en humanos. . $^{31,32}$

Chancroide. El H. ducreyi produce una citotoxina que es responsable de la lesión en el epitelio escamoso y que conduce a la formación de la úIcera. La toxina puede ser neutralizada en forma semejante a lo que ocurre con la toxina diftérica. Se han identificado otras proteínas incluyendo las de la membrana externa y las de fimbrias (pilinas), el problema es su gran variación antigénica durante la infección. La inmunidad que induce está mediada por células T y B. ${ }^{33,34}$

Gonorrea. Se han identificado varias proteínas en forma semejante a lo realizado con la membrana externa de otras bacterias gramnegativas (OPA), del lipopolisacárido (LOS), porinas (Por) y pilinas (Pil). Se pretende 
utilizar aquellos inmunógenos que no presenten grandes variaciones antigénicas. La proteína Por parece ser el candidato para la vacuna que por ahora es más popular. ${ }^{31,33}$

Clamidia. Es la causa más frecuente de las uretritis, cervicitis y salpingitis, con repercusiones perinatales importantes. Con la tecnología de la biología molecular se han diseñado algunas proteínas interesantes; la más actual es la proteína de la membrana externa (MOMP), la que se ha clonado y secuenciado para identificar varios dominios que comprenden a los diferentes serovares de las clamidias, inducen inmunidad en mucosas e impiden la adherencia cuando se utilizan en animales de experimentación como ratones y monos. ${ }^{31}$ Herpes genital. Las vacunas que se han diseñado son para prevenir la infección, reducir la transmisión a los susceptibles y suprimir o prevenir la expresión de la enfermedad. La vacuna no debe estar restringida solamente a los grupos considerados de alto riesgo, debe incluir a la población con recurrencias incluso del herpes oro-labial, y producir inmunidad de larga duración contra los VHS-1 y VHS-2. Las vacunas que se han desarrollado incluyen las glicoproteínas superficiales $\mathrm{gB}$ y gD como antígenos, y las más actuales utilizan la tecnología de biología molecular recombinante. La última vacuna recombinante $\mathrm{gD} 2$, en estudios de casos y controles, reduce las recurrencias de la enfermedad. Si se demuestra su seguridad y eficacia podría considerarse como una alternativa en función de costo-beneficio, sobre todo cuando se compara con el uso del aciclovir con los mismos propósitos. ${ }^{35,17}$

Papilomatosis genital. La infección genital es muy frecuente y generalmente asintomática. El riesgo de adquisición entre las parejas sexuales es muy elevado. Por ahora el interés está relacionado con la participación de los subtipos 16, 18, 31 y 45 como cofactores importantes en el cáncer cervicouterino.

Se plantea la necesidad de garantizar que la vacuna aporte inmunidad mediante varios mecanismos: expresión de antígenos presentes en la célula; producción de inmunidad mediada por células T y B, así como la prolongación de la inmunidad por largo tiempo. Los avances recientes utilizan como vector al virus de la vaccinia con las proteínas E6 y E7 del virus del papiloma humano. ${ }^{36}$ Los resultados preliminares son halagadores y especulan a corto plazo la obtención de un inmunógeno de calidad y potencia óptimas.

\section{Referencias}

1. C alderón JE. Impacto de las enfermedades transmitidas sexualmente en la salud reproductiva. En: Ayala RA, ed. Medicina reproductiva humana. México, D.F.: G rupo Azabache, 1996:584-597.
2. Conde-González C. Enfermedades de transmisión sexual. PAC Infecto1 (monografía). México, D.F.: Intersistemas, 1999.

3. Arredondo GJ, N arcio RL, Casanova RG, Figueroa DR. Enfermedades transmitidas sexualmente (ETS) en un grupo de adolescentes que asisten a un instituto de atención perinatal. Gac Med Mex 1993;129:75-79.

4. Uribe-Salas F, Hernández-G irón AC, C onde-G onzález C, C ruz-Valdez A, Juárez-Figueroa L, Hernández-A vila M. C aracterísticas relacionadas con ETS/VIH de hombres que trabajan en bares de la Ciudad de México donde se ejerce la prostitución femenina. Salud Publica Mex 1995;37: 385-393.

5. C alderón JE, Conde-González C. Enfermedades de transmisión sexual. En:Arredondo GJ, Calderón JE, ed. Conceptos clínicos de infectología. México, D.F.: Méndez Editores, 1993:133-149.

6. U ribe SF, Hernández AM, C onde-G lez C , Juárez L,A llen B,A naya $R$ et al. Low prevalences of HIV infection female commercial sex workers in Mexico City.Am J Public Health 1997:87:1012-1015.

7. Juárez $\mathrm{FL}$, U ribe $S F, C$ onde- $\mathrm{Glez} C$, H ernández AM, $O$ lamendi PM, U ribe $Z P$ et al. Low prevalence of hepatitis $B$ markers among Mexican females sex workers. Sex Transm D is 1998;74:448-450.

8. 1998 G uidelines for Treatment of SexuallyTransmitted Diseases. MMW R Morb Mortal W kly Rep 1988;47(RR-1).

9. Hernández GC, U ribe SF, C onde G-C , C ruzVA, Juárez FL, U ribe ZP et al. Seroprevalencias a diversos virus y características sociodemográficas en mujeres que buscan detectarse VIH. Rev Invest Clin 1997;49:5-13.

10. Casanova RG, 0 rtiz IF,Arredondo GJ. Las enfermedades de transmisión sexual: causa de complicaciones perinatales. Enferm Infec Microbiol 1994; 14:25-28

11. Behets FM, Brathwaite AR, Hylton-Kong T, C hen CY, H offman I, W eiss JP et al. Genital ulcers: Etiology, clinical diagnosis, and associated human immunonodeficiency virus infection in Kingston, Jamaica. Clin Infect $D$ is 1999:28:1086-1090.

12. Trees DL, Morse SA. Chancroid and Haemophilus ducreyi. An update. Clin Microbiol Rev 1995;8:357-375.

13. Schmid GP. Treatment of chancroid. C lin Infect D is 1999;28 suppl 1: 14-20.

14. Corey L. Genital herpes. En: Holmes KK, Mardh PA, Sparling PF,W ierner PJ, Cates Jr W, Lemon SM, ed. Sexually transmitted diseases. 2a. edición. N ueva York: McG raw Hill, 1990:391-413.

15. Conde-G lez CJ, Juárez FL, U ribe SF, Hernández N P, Schmid DS, C alderón $\mathrm{E}$ et al. Analysis of Herpes simplex virus 1 and 2 infection in women with a high risk sexual behavior in Mexico. Int J Epidemiol 1999;28. En prensa.

16. C astelazo ME, Calderón JE, N asrallah RE. Espectro clínico de los herpetovirus durante la etapa perinatal. En: Calderón JE,Arredondo GJ, Karchmer KS, Nasrallah RE, ed. Infectología perinatal. México, D.F.: Trillas, 1991:103-118.

17. W ald $A$. N ew therapies and prevention strategies for genital herpes. Clin Infect D is 1999;28 suppl 1: 4-13.

18. Sparling PF. N atural history of syphilis. En:H olmes KK, Mardh PA, Sparling PF,W iesner PJ, Cates Jr W, Lemon SM, ed. Sexually transmitted diseases. 2a. edición. N ueva York: McG raw Hill, 1990:213-219.

19. Calderón JE, Solórzano SF, Nasrallah RE. Sífilis prenatal y postnatal reciente sintomática. En: C alderón JE,Arredondo GJ, Karchmer KS, N asrallah RE, ed. Infectología perinatal. México, D.F.:Trillas, 1991:64-75.

20. U ribe SF, D el Río CC, C onde-G lez C, Juárez FC, U ribe ZP, Calderón JE et al. Prevalence, incidence and determinants of syphilis in female commercial sex workers in Mexico C ity. Sex Transm D is 1996;23:120-126.

21. Calderón JE, C onde GC , Juárez FL, U ribe ZP, U ribe SF, $O$ lamendi PM et al. Prevalencia de anticuerpos antitreponémicos en 3098 mujeres dedicadas a la prostitución en la Ciudad de México. Rev Invest Clin 1994;46: 431-436.

22. Augenbraun MH, Rolfs R. Treatment of syphilis, 1998: N onpregnant adults. $C$ lin Infect $D$ is 1999; 28 suppl 1:21-28. 
23. Conde-G onzález C, U ribe SF. G onorrea: la perspectiva clásica y la actual. Salud Publica Mex 1997;39:573-579.

24. De la Cruz GR, Conde-González CJ, Calderón JE, Hirata VC, N arcio RL, Sánchez MR.Utilidad del examen microscópico para el diagnóstico de gonorrea. Salud Publica Mex 1987;29:190-194.

25. Calderón JE, Conde-G lez CJ, De la Cruz GR, N arcio RL, Hirata VC. Treatment of ordinary and penicillinase producing strains of Neisseria gonorrhoeae in Mexico City. Diagn Microbiol Infect D is 1987;8:13-18.

26. Calderón JE, Conde-G lez CJ, Echániz AG, Arredondo JL, O lvera J, $\mathrm{H}$ irata $\mathrm{C}$ et al. Results of treatment of uncomplicated urogenital gonorrhoeae with enoxacin compared with ceftriaxone. J Clin Pharm Res 1988;8:247-251.

27. Burstein GR, Zerulman JM. N ongonococcal urethritis. A new paradigm. Clin Infect $D$ is 1999;28 suppl 1:66-73.

28. Yánez VL, Gatica MR, Salinas VL, Figueroa AP, C alderón JE. Infección durante el embarazo como factor causal de ruptura prematura de membranas y de parto pretérmino. Salud Publica Mex 1990;32:288-297.

29. Tamayo E, Echániz AG, Cruz A, C amacho AG, Calderón JE. Infección por el virus del papiloma humano en mujeres con y sin citología cervical anormal. Ginecol 0 bstet Mex 1993;61:27-34.
30. Beutner KR,W iley DJ, D ouglas JM, Tyring SK, Fife K, Trofatter $K$ et al. Genital warts and their treatment. $C$ lin Infect $D$ is 1999;28 suppl 1:37-48. 31. Barbosa-C enik C, Gerbase A, Heymann D. STD vaccines:An overview. Genitourin Med 1997;73:336-342.

32. Sell S, H su PL. D elayed hypersensitivity, immune deviation, antigen processing and T-cell subset selection in syphilis pathogenesis and vaccine design. Immunol Today 1993;14:576-582.

33. Sparling PF, Elkins $C, W$ yreick PB, Cohen MS. Vaccines for bacterial sexually transmitted infections:A realistic goal. Proc N atl Acad Sci U SA 1994;91:2456-2463.

34.A dimoraAA, Sparling PF, C ohen MS.Vaccines for classic sexually transmitted diseases. Infect $D$ is C lin N orth Am 1994;8:859-876.

35. Bruga R, Keersmaekers K, Renton A, Meheus A. Genital herpes infection:A review. Int Epidemiol Assoc 1997;26:698-710.

36. Berumen J, Villegas $N$. Vacunas terapéuticas recombinantes contra el cáncer del cuello uterino. Salud Publica Mex 1997;39:288-297. 